\title{
The Impact of Peer Learning on Student Performance in an Architectural Sustainability Course
}

\author{
M. Amparo Núñez-Andrés \\ Department of Civil and Environmental Engineering, Universitat Politècnica de Catalunya, Barcelona, Spain \\ Antonio Martinez-Molina \\ Department of Architecture, The University of Texas at San Antonio, San Antonio, USA \\ Núria Casquero-Modrego \\ Residential Building Systems Group, Lawrence Berkeley National Laboratory, Berkeley, California, USA, and \\ Jae Yong Suk \\ Department of Architecture, The University of Texas at San Antonio, San Antonio, USA
}

\begin{abstract}
Purpose - The importance of sustainability in architecture currently necessitates the integration of innovative teaching strategies on the subject into architecture programs. This study introduces and examines peer learning pedagogy by peer tutoring to educate architecture students in sustainable design.

Design/methodology/approach - Based on class assignments proposed in two different architecture sustainability-focused courses in the second and fourth years of the B.S in Architecture program, a total of 103 students assessed the proposed peer learning experience and its impact on their sustainability mindsets and education. Subjective surveys for evaluating the peer learning experience were designed and delivered at different stages of the course sequences. A total of 502 survey responses were obtained in the study.
\end{abstract}

Findings - The qualitative and quantitative data analysis confirms that the proposed peer learning by peer tutoring increased students' knowledge, motivation, and commitment to sustainable design. In addition, participants became more confident in applying sustainable design skills and their academic grades improved more than $25 \%$ compared to previous courses using traditional teaching methods.

Originality - Traditional architecture education has long been criticized for their pedagogical methodologies based primarily on passive learning. Recently, these programs have begun to prepare students to become active learners and communicators in collaborative and multidisciplinary environments. A mixed-method approach of combining pre-/postexperience surveys and analysis of final grades was used to determine the level of success and the quantifiable behavior change delivered by students involved in this peer learning experience. 
Keywords: Architectural Education; Sustainable Design; Peer Learning; Peer Tutoring; Collaborative Learning; Cooperative Learning.

\section{Introduction}

Since society values sustainable development, it is essential to introduce and promote these important changes and improvements in the quality of higher education (Leal Filho et al., 2019). The growing awareness and influence of sustainability in the built environment has pushed architecture programs to incorporate sustainable design topics into the educational structure (Boarin et al., 2020). Traditional architectural and engineering teaching methodologies are primarily based on passive learning and have been frequently criticized by many authors due to their ineffectiveness in engaging students into professional practices (Stump et al., 2011). In order to overcome this problem, many universities have approached the teaching of sustainable design in varied ways (Disterheft et al., 2016). Clearly, it is necessary to introduce new pedagogies to teach and motivate students in this important topic. At present, architectural education is mainly based on Project-Based Learning ( $\mathrm{PBL})$, where students are asked to design and develop a proposal which follows the regular workflow implemented in a real architectural studio (Corral Manuel de Villena et al., 2012; Valls et al., 2018). An especially relevant study conducted by Mavromatidis (Mavromatidis, 2018) applied a methodology to incorporate sustainability into architectural education by combining three educational models of architectural synthesis, including 1 ) professionalist method, 2) theorized method, and 3) scientific method. It is noteworthy to mention that existing studies reported benefits from the interaction among students that share the same level of knowledge. In this way, they develop a new perception of the course topic and also improve observations among themselves (Stump et al., 2011; Webb, 1989). This is the case of collaborative and cooperative learning methodologies, which have very similar approaches, the main difference is that the students learn in cooperation with others in order to gain knowledge (Salmerón et al., 2010). The present study explores a new learning experience by introducing peer tutoring in a course of sustainable design. The proposed learning experience seeks to involve students' intellectual engagements of two different course sequences that require different levels of knowledge. Additionally, this peer learning by peer tutoring methodology aims to assess students' interactions and skills which 
were emphasized in an active learning environment such as collaborative and cooperative pedagogy. With its focus on higher education, the study aims to contribute to the conversation of peer learning by peer tutoring in architectural education.

\section{Literature Overview}

Teaching sustainability topics is based on transmitting concepts and processes, and it requires a more interactive pedagogical process for successful learning experiences (Barth and Michelsen, 2013). As peers who have been in a similar learning situations would have faced similar problems, learning from colleagues is an effective methodology that has been used for centuries and directly meets leaners' needs or solves their immediate problems (Boud, 2001; Keppell et al., 2006). This peer learning process has been actively adopted by the educational community to assess both learning outcomes and interactional dynamics of students (Haller et al., 2000; Huang and Pierce, 2015; Webb, 1989). This student interaction can occur among students in the same course with different knowledge levels or among students in different courses where students in an upper-level course tutor students of lower courses.

The term peer learning represents sharing knowledge, concepts, ideas, and experience among diverse people in similar situations (Boud, 2001; Keppell et al., 2006). Authors including Boud (Boud, 2001) describe peer learning as a way of moving beyond independent to interdependent or mutual learning among peers. It is defined as a way to acquire knowledge with the active help and support of a group of peers. With peer learning, both students (or learners) and tutors (or mentors) take advantage of the multi-directional exchange of information (Topping, 2015). Moreover, previous studies state the positive psychologically aspects of peer learning on students, including increased confidence, competence (Stone et al., 2013), and decreased anxiety (Rodarte-Luna and Sherry, 2008). However, there is a concern about using peer learning during students' creative development process (Budge et al., 2013). The existing scientific literature shows confusion between peer "tutoring" and peer "mentoring". Therefore, it is important to explain the different definitions. Peer mentoring is a supportive one-to-one relationship with a more experienced worker in a joint area of interest. On the other hand, peer tutoring involves specific role-taking as a tutor or tutee who follow given procedures for interaction and 
curriculum content. As adopted in this study, peer tutoring requires participants to receive generic and/or specific training (Topping, 2015). In a study on peer learning and peer tutoring, researchers identified ten different learning models (Griffiths et al., 1995). One of the learning models is a traditional approach where senior students tutor juniors. However, a more innovative approach requires students in the same year to collaborate and help each other with course work and personal concerns. Another inventive learning approaches include discussion seminars, peer-assessment schemes, collaborative projects, or laboratory work. It is noted that neither peer learning nor peer tutoring have been researched enough in workplaces (Topping, 2015). Over the years, some authors have assessed peer learning models in teaching diverse areas of knowledge, such as: research education (Boud and Lee, 2005); mathematics education (Cheng and Walters, 2009); clinical education in health sciences (Secomb, 2008); nursing education (Stone et al., 2013); nutrition education (Dehghani et al., 2014); language education (Evnitskaya, 2008); use of peer learning in technology (Fateh Ali Khan et al., 2018); use of peer learning in workplaces (Martin and Edwards, 1998). In general, there is a dearth of literature focused on peer learning in the degree of architecture. However, some publications such as Nicol and Pilling's (Nicol and Pilling, 2005) in its chapters 1, 2, and 4, and Pelsmaker's (Pelsmakers et al., 2019) have tried to take a step forward on this topic to improve architecture courses. Little research has been conducted in architecture, and far less in education in sustainable design. For this reason, the present study aims to investigate peer learning pedagogy by peer tutoring, particularly in sustainable architecture courses in higher education. Findings from this study will help advance future teaching methods and improve academic performance in sustainable architecture courses.

\section{Research Approach}

In this study, a sustainability project using peer learning pedagogy was developed to enrich active learning with two very well-defined goals: a) strengthening tutors' communication skills; and b) increasing tutees' knowledge in sustainable design topics. Thus, this study proposed an assignment in the course Principles of Environmental Systems (ARC2233), offered at The University of Texas at San Antonio in the second year of the Bachelor of Science (B.Sc.) in Architecture (pre-professional program). Two different student courses 
participated in the case study, 2nd year students (ST2) that took the course (ARC2233) in Fall 2019, and 4th year students (ST4) that took the more advanced course of Environmental Systems (ARC4183) also in Fall 2019, but previously took (ARC2233) course in Spring 2019 or Fall 2018. The presented study incorporates an innovative double peer learning experience into two different courses with different levels of student knowledge. In order to assess and understand student engagements of peer learning and peer tutoring in an architecture course of sustainable design, the study looked at two types of peer learning interactions (Haller et al., 2000): 1) Collaborative and cooperative interaction, in which students are free to work together without any specific roles being assigned; and 2) Transfer-of-knowledge interaction, in which students adopt teacher/pupil roles (i.e. tutor and tutee role). There was a concern that this interaction might cause problems for students taking the role of pupil (i.e. tutee) as it can discourage contributions from others. However, the present case study overcomes the problem as the students taking the teacher's role (i.e. tutor) are the students from an advanced course.

Table 1. B.Sc. in Architecture course structure with highlighted sustainability courses.

\begin{tabular}{|c|c|c|}
\hline & Semester 1 & Semester 2 \\
\hline \multirow{5}{*}{$\begin{array}{l}\stackrel{-1}{\grave{d}} \\
\stackrel{d}{>}\end{array}$} & AIS1203 - Academic Inquiry & ARC1224 - Design II \\
\hline & $\begin{array}{l}\text { ARC1113 - Introduction to the Built } \\
\text { Environment }\end{array}$ & $\begin{array}{l}\text { ARC1513-Great Buildings and Cities of the } \\
\text { World }\end{array}$ \\
\hline & ARC1213 - Design I & WRC1023 - Freshman Composition II \\
\hline & ARC1313 - Design Visualization & Mathematics Core \\
\hline & WRC - Freshman Composition & Life \& Physical Sciences Core \\
\hline \multirow{4}{*}{ 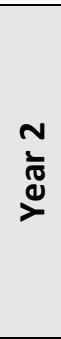 } & $\begin{array}{l}\text { ARC2133 - Principles of Architectural } \\
\text { Structures }\end{array}$ & ARC2166 - Digital Design Studio \\
\hline & $\begin{array}{l}\text { ARC2233 - Principles of Environmental } \\
\text { Systems }\end{array}$ & ARC2423 - History of Architecture II \\
\hline & ARC 2156 - Drawing and modeling Studio & $\begin{array}{l}\text { CSM2113 - Construction Materials and } \\
\text { Methods }\end{array}$ \\
\hline & ARC 2413 - History of Architecture I & Social \& behavioral Sciences Core \\
\hline \multirow{4}{*}{$\begin{array}{l}m \\
\frac{1}{\mathbb{D}} \\
\stackrel{2}{2}\end{array}$} & ARC 3613 - History of Modern Architecture & ARC 4156 - Building Design Studio \\
\hline & $\begin{array}{l}\text { ARC } 4833 \text { - International Studies Drawing } \\
\text { Seminar }\end{array}$ & American History Core \\
\hline & $\begin{array}{l}\text { ARC4843 - International Studies History } \\
\text { Seminar }\end{array}$ & Government-Political Science Core \\
\hline & ARC 4616 - International Studies Studio & - \\
\hline \multirow{2}{*}{$\begin{array}{l}\text { 寸 } \\
\text { ர্ } \\
\stackrel{0}{2}\end{array}$} & $\begin{array}{l}\text { ARC } 3433 \text { - Topics in Architecture and } \\
\text { Thought }\end{array}$ & ARC 4246 - Systems Studio \\
\hline & ARC 4156 - Building Design Studio III & ARC 4283 - Architectural Structures \\
\hline
\end{tabular}


The course structure of the B.Sc. in Architecture program is shown in Table 1. It is noteworthy that both courses (ARC2233 and ARC4183) belong to the same sustainable architecture course sequence. However, ARC2233 serves as a basic course that introduces the principles of sustainable architecture while (ARC4183) is an advanced version of (ARC2233) that applies known sustainable design knowledge and skills to building design procedures. For this reason, ST4 students took a role of tutors and were used as a control group. The grades of the ST2 students (tutees) were compared with those of the control group, ST4. In this study, the size of the work group was defined by the following premises: a) limiting a number of students in each ST2 group to prevent students from taking advantage of their groupmates (Slavin and Johnson, 1999); b) allowing multiple students in each ST2 group to complete the assignment correctly; and c) as this was the first time for the ST4 students to participate in a tutoring activity, they were asked collaborate in pairs as a way to reduce anxiety for tutoring the ST2 students (Stone et al., 2013). ST4 students agreed in advance the guidance they should provide to the ST2 students. Consequently, it was intended that ST2 students could develop the skills of confidence, competence, and knowledge. It was necessary to reach a balance of numbers of tutors and tutees. For this reason, ST2 students worked in teams of three members tutored by a group of two ST4 students. Tutors and tutees were paired randomly in order to avoid personal connections between the two groups so that the interaction between tutors and tutees is focused on the teaching-learning process, not personal issues. ST2 students worked on an assignment focusing on learning and applying the sustainable design knowledge they learned in class while developing their confidence and knowledge generated by team communication. On the other hand, ST4 students' activity was concentrated on developing competence skills that are needed in real professional environments, such as communication of technical concepts, project management, conflict resolution, etc. It has been proven that these targeted skills are easier for students to acquire by working in small groups of students rather than larger groups (Finelli et al., 2001). 


\section{Content and Process of the Activity}

These parallel activities aim to target the sustainability scope of Sustainable Development Goals (SDG) such as \#11 Sustainable Cities and Communities (United Nations General Assembly, 2015) aiming to understand buildings that lessen their impact on our environment through energy and resource efficiency. The project goal assigned to the ST2 students was to conduct extensive research of an existing building that represents sustainable architecture and passive design strategies while the ST4 students mentor them and reinforce the knowledge gained in past years. As depicted in Table 2, this group assignment is consisted of mainly three parts: a) producing a report of a case study building; b) building a physical model, and c) giving a 15-minute presentation analyzing the selected building's sustainable features followed by a Questions and Answers (Q\&A) session.

Table 2. Milestones and outputs of ST2 and ST4 activities.

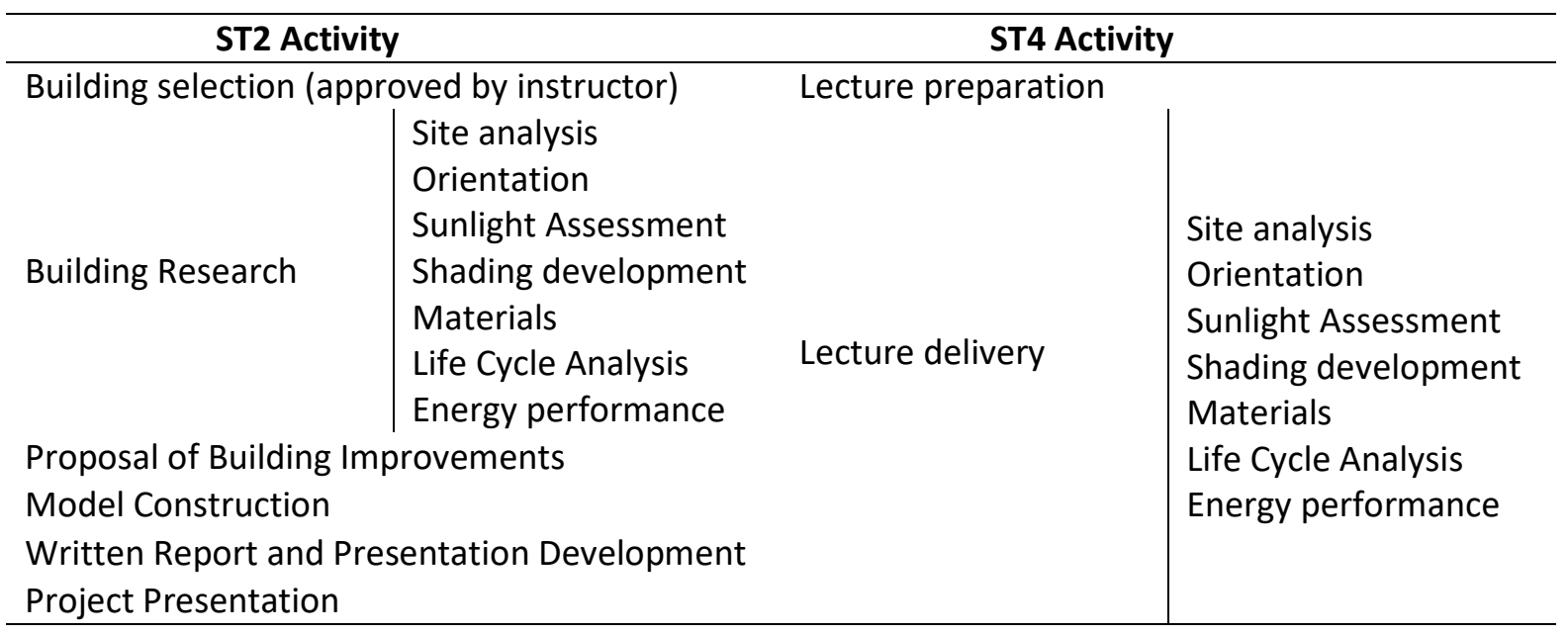

As shown in Figure 1, the assignment was scheduled during four weeks, from October 31st to November 21st, 2019, as follows: a) prior to the assignment, the professors explained the peer learning and peer tutoring content and rules to both ST2 (tutees) and ST4 (tutors); b) during the first week, all the assigned ST2 and ST4 students attended a kickoff meeting where tutors clarified the needed basic theory and procedure to complete the assignment. In addition, the ST2 students outlined a schedule to develop the specific tasks based on the course timeline and their roles; c) during the second week, the ST2 students had a 30- to 60-minute-long follow-up meeting with the ST4 students to report any difficulties they encountered and to learn potential solutions, if needed; and d) during the 
third- and fourth-weeks, tutors helped resolve ST2 students' doubts and confirmed that they followed the planned chronogram. The ST4 students tutored and guided the learning process of the ST2 students without directly contributing the assignment activities. In addition to in-person meetings, online tutoring sessions were held to help resolve doubts or questions that came up along the third- and fourth weeks when the students had more autonomy. Each ST4 tutor group was directed to document the questions and answers as evidence of online consultation that they provided.

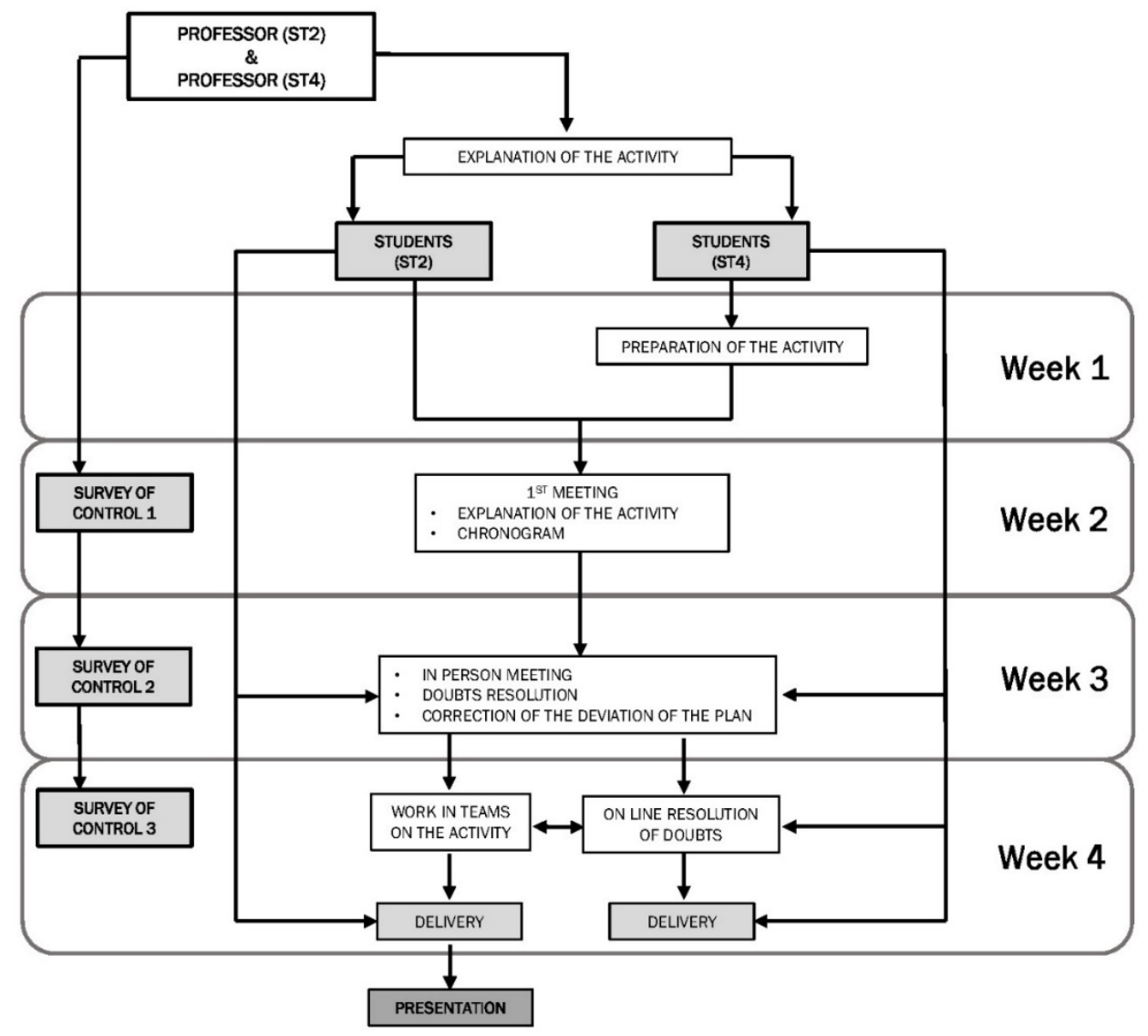

Figure 1. Schedule and timeline of the conducted activity.

To monitor the development of the peer learning and tutoring activity, each team had 5-10-minute weekly meetings with the professor to review the progress and identify internal conflicts within the ST2 teams before the project deadline. Moreover, both ST2 and ST4 students were required to answer a weekly follow-up online survey. This progress checkup helped to identify any problems that the students might have not mentioned to the professors. The professor, after reviewing the results of the follow-up surveys of the teams, 
asked for a meeting with the students in order to resolve internal conflicts in the ST2 students' teams. Figure 2 shows some examples of students' work that present the scope

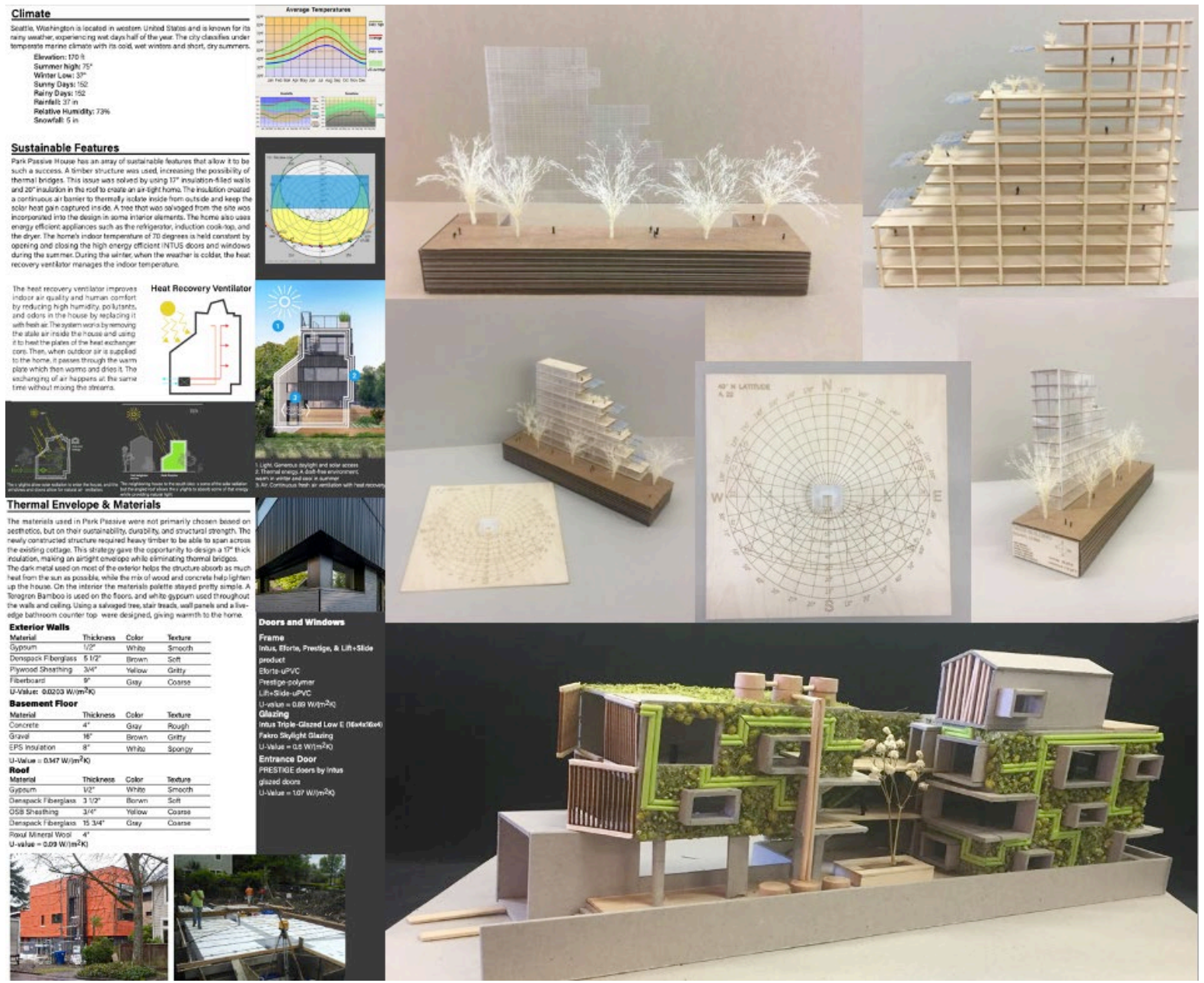

and learning outcomes of the given assignment.

Figure 2. Examples of ST2 students' work.

\section{Survey}

Subjective survey was conducted to assess student interactions and gain a better understanding and feedback of peer learning pedagogy from architecture students in sustainable design courses. Three independent surveys were conducted before, during, and after the peer learning by tutoring in order to collect the students' subjective opinions. ST2 and ST4 students had different surveys developed for the singular aspects of their roles, but in similar format. The three surveys took place on November 6th, 12th and 22nd 2019.

The three surveys are composed of a total of 23 and 26 questions in five distinctive sections as follows, respectively for ST2 and ST4: a) General information; b) Learning and 
growth; c) Peer learning; d) Collaborative learning (this section included an open-ended question); and e) Students' Evaluations of Educational Quality (SEEQ). These surveys seek to assess both ST2 and ST4 students in peer learning by peer tutoring and peer learning within teamwork, specifically: 1) What is the effect of the peer learning on students' skills when the role is a tutor? 2) What is the impact of the peer learning on students' knowledge when the role is a tutee? and 3) How does the peer learning benefit students' learning in courses of architectural sustainable design? The questions in each section were developed based on the existing scientific literature: a) Peer Learning: Webb (Webb, 1989), Haller et al. (Haller et al., 2000), Boud et al. (Boud et al., 2002), Huang et al. (Huang and Pierce, 2015); b) Collaborative learning: Stump et al. (Stump et al., 2011); and c) SEEQ: Marsh (Marsh, 1982). As mentioned above, the 3rd survey took place after the project deadline and before final grades of the course were provided. Therefore, the students' feedback was not influenced by final grades of the course.

\section{Students' Assessment}

The guidelines to grade the ST2 and ST4 students were different since their learning objectives in the courses were different as well. Tutors' grades (ST4 students) were based on their successful tutoring and guidance with only the input of their instructor. On the other hand, ST2 students, tutees, were graded based on the input received from the professor as well as the feedback from their classmates and tutors. This grading methodology is based on Sanmartí (Sanmartí, 2007) who understands that grading is a process that interacts three different elements: the professor, the students themselves, and the classmates. However, the professor is the one who has the most impact over the students' final grade. The proposed grading methodology in this study was based on the "alternative grading" (Álvarez Valdivia, 2008) which relies on real hands-on experiences without any final or objective exam. The grading of this activity was the $25 \%$ of the final grade of the course for the ST2 students, and it was divided into:

- $33.3 \%$ of the final grade of the activity came from the professors' assessment;

- $33.3 \%$ of the final grade assessment came from the ST4 tutors; and

- $33.3 \%$ of the final grade assessment came from the activity set by the other ST2 students' teams. 
After turning in the assignment report, the grading among the ST2 students was carried out by the professor, including feedback coming from the ST4 students. This grade was included into the final grade of the students' course. All the participating students had the grading rubrics: 1) the rubric of their team; 2) the rubric of the other teams; and 3) the professor's rubric. To avoid a subjective evaluation by the students, a rubric was developed for the internal co-evaluation of each group and another for the evaluation of the rest of the groups. All three rubrics are different, rubrics 1) and 2) focus on assessing general competences such as teamwork, communication skills, critical thinking, etc., while rubric 3 ) is focused on knowledge evaluation. Therefore, everyone in a same team was clear about the requirements that the professor asked for in the delivery of the assignment. For the ST4 students, their grading on the peer tutoring represents $7 \%$ of their final grade of the course, and it was divided into: a) $80 \%$ of the assignment grade is from the professors' assessment on the report and the Questions/Answers documentation; b) $20 \%$ of the assignment grade assessment is from the three surveys participation.

\section{Results}

This section presents the results of the qualitative and quantitative data collected through two different surveys, which evaluated students' subjective opinions and their interactions in a peer learning by peer tutoring conducted in sustainable architecture courses. A total of 103 students participated in the surveys: 61 ST2 students (as tutees) and 42 ST4 students (as tutors). A total of 502 answers (311 from ST2 students and 191 from ST4 students) were collected. The surveys were extensive and detailed containing 23-26 questions, however, only the most relevant topics based on students answers and opinions were included in this results section. Three comparisons were made in addition to the open-ended field for students' comments: a) Comparison of ST2 student opinions before and after the peer learning by peer tutoring; b) Comparison of ST4 student opinions before and after the peer learning by peer tutoring; c) Comparison of ST2 and ST4 student performances and interactions in the peer learning by peer tutoring. Since student participation was robust with a response rate of $97.5 \%$, the collected data is considered a representative of the analyzed course population. Students in both courses had practically the same 
characteristics as follows: $80 \%$ of the participants were between 18 and 24 years of age and around $75 \%$ of the participants were from the USA. The only noteworthy discrepancy in the population was the gender distribution of the ST2 students ( $32 \%$ males and $68 \%$ females) as compared to the ST4 students (55\% males and $45 \%$ females). Additionally, students' responses were evaluated before and after this experience by using a Paired-t test analysis. If $p$ is smaller than the significance level or $\alpha$ (default is 0.05 ), then the corresponding correlation in $r$ is considered significant.

\section{Comparison of ST2 Student Opinions before and after Peer Learning}

When asked about their motivation before the peer learning experience, the students showed great enthusiasm with $97 \%$ of the students replying that they will take an active role in their respective groups. It is very significant that $60 \%$ of the ST2 participants replied that they expected to have a role equal to that of their teammates while $25 \%$ of them replied that they will try to lead their group and only $15 \%$ decided to take a passive role. Although all groups appeared to have student leaders, most of the participants planned on having equal interactions with a team leader rather than a hierarchical relationship. This demonstrates that the teamwork spirit of each group would not be negatively influenced by an individual team member or leader. Analysis of the ST2 student responses before and after the peer learning assesses perception of learning from the tutee's perspective. As shown in Figure 3, students were fairly optimistic in their expectations. $37.3 \%$ and $45.8 \%$ of the students expected medium and high success rates, respectively. Nevertheless, after participating in the activity the success rates increased even higher to a total of $90.3 \%$ answers falling in the range of high or very high. After the paired-t test the $t$ value is 0.62 , therefore the difference before and after the activity can be considered statistically significant. 


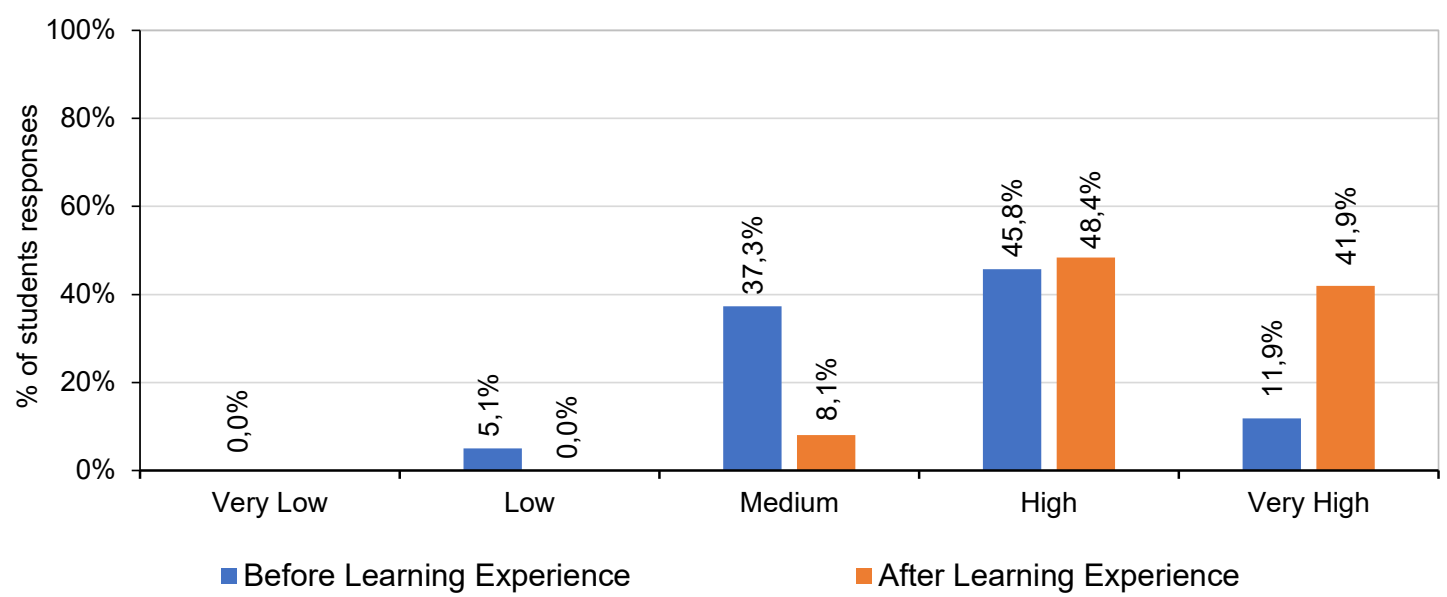

Figure 3. Results from ST2 students to question: How do you think that your theoretical and/or practical education has prepared you for your task within this activity?

In order to investigate student success, students were asked before and after the assignment about the information sources they expected to use and ultimately used. As depicted in Figure 4, students thought, prior to the assignment, that either the instructor (33.9\%) or the internet $(28.8 \%)$ were going to be the main sources of information (one or the other, not both). After the peer learning experience, the students realized that their expectations were erroneous and instead chose the multi-source option (over $50 \%$ of responses). This switch might be a consequence of peer learning by peer tutoring. While it is challenging to verify, this is still a positive sign since it increased critical thinking and students looked for several points of view about the topic that they were working.

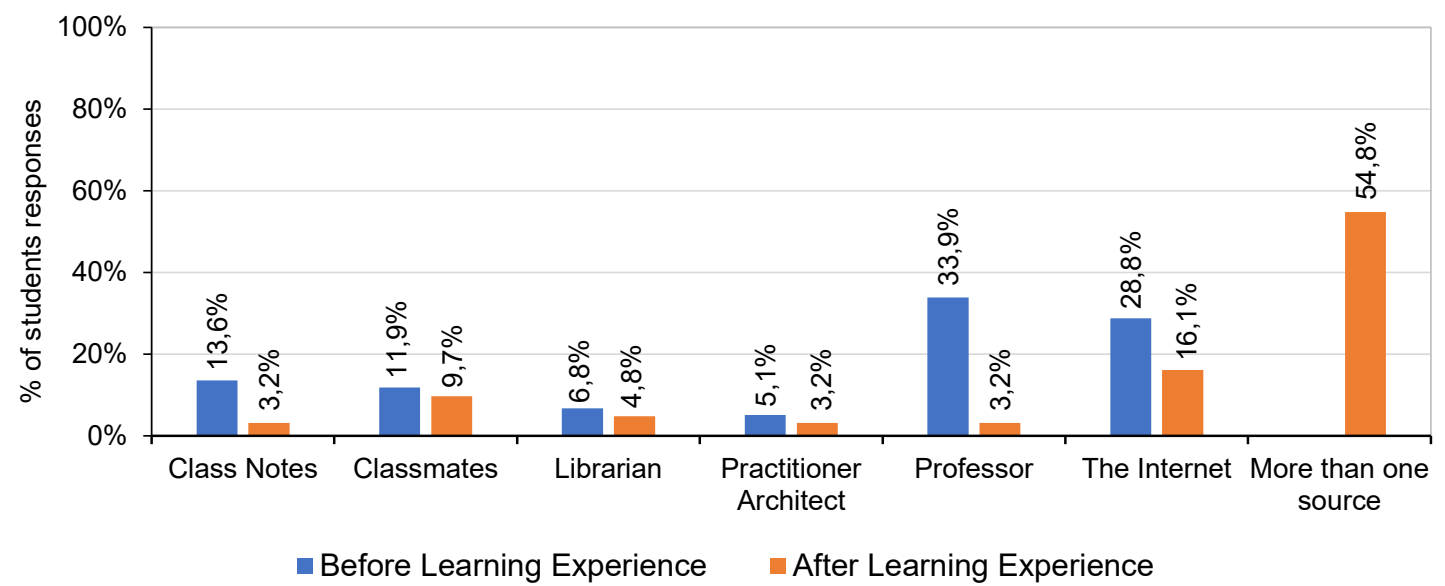

Figure 4. Results from ST2 students to question: From whom / where do you obtain the information to resolve an academic/course question? 
Figure 5 shows that a large number of students thought that this peer learning experience would not greatly improve their interest in the course topics and sustainability in general. This explains that the students were already very interested in the course topics prior to taking the course and participating in peer learning by peer tutoring as positive responses are at $61 \%$ (before) and $71 \%$ (after) respectively. Following the same pattern, statistically speaking the level of interest in the sustainability did not changed dramatically since the paired-t test result show a $t>0.05(0.52)$, therefore the difference is considered not significant.

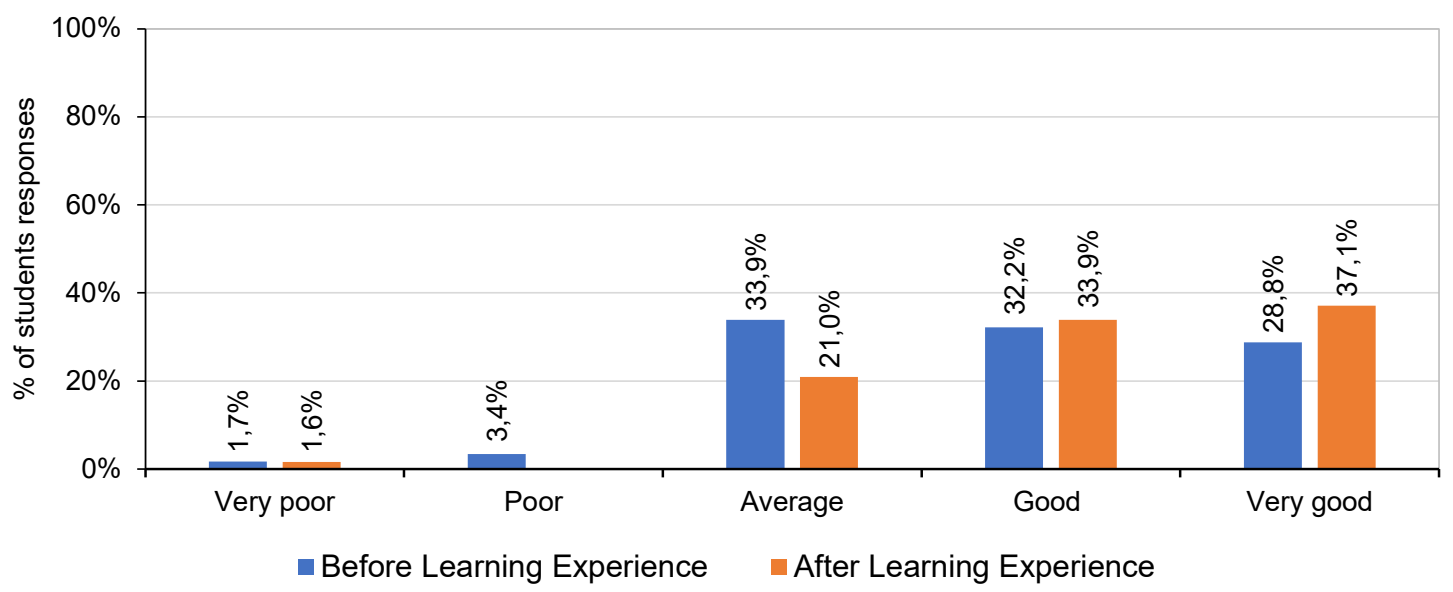

Figure 5. Results from ST2 students to question: Level of interest in this class after this peer learning exercise?

The success of a non-standard teaching strategy, such as peer learning by peer tutoring, can be measured in multiple ways; however, the most meaningful measure is the growth of student knowledge and commitment to the course subject after the peer learning experience. Figure 6 represents student opinions to these questions. For the most part, the ST2 students experienced a remarkable increase in both knowledge and commitment to sustainable design with over $74.2 \%$ and $66.1 \%$ respectively. In this achievement, the tutors' inputs played a critical role with a $15 \%$ increase in tutees (ST2) trusting their tutors (ST4). Additionally, after this new learning experience, the ST2 students also raised their opinions on how much this sustainability course prepared them as future professionals by $22 \%$. 


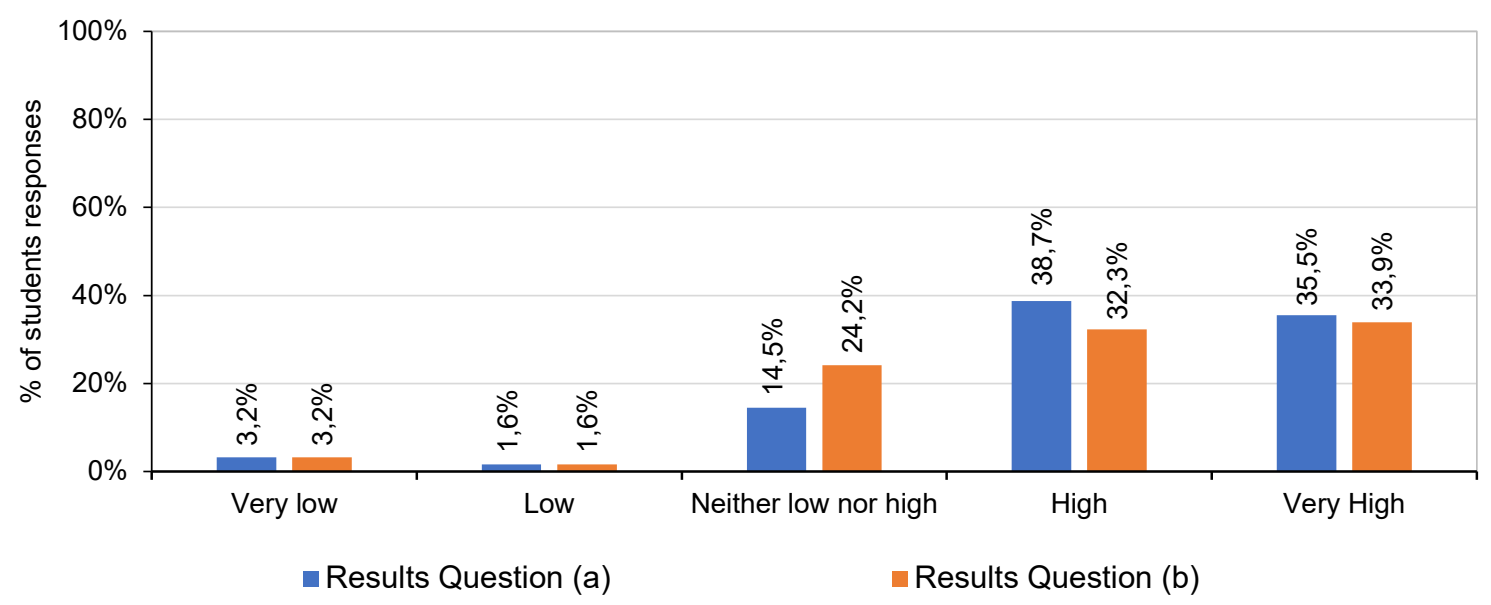

Figure 6. Results from ST2 students to questions: a) To what extent does the proposed peer learning strategy improved your understanding of Sustainable Design? b) To what extent does the proposed peer learning strategy changed your attitude toward Sustainable Design?

Comparison of ST4 Student Opinions before and after Peer Tutoring

Results in Figure 7 show that before the peer learning by peer tutoring experience, the answers of the tutors were very similar to those of the tutees with respect to the choices of the main information sources (not in actual percentages) expected to be used before the activity, focusing their options on the internet (34.2\%), the instructor $(23.7 \%)$, and class notes (21.1\%). Surprisingly, after the peer tutoring experience, unlike ST 2 students, $41.2 \%$ of the ST4 students used their own class notes as the main source of information, together with their classmates $(20.6 \%)$ and the professor (17.6\%). The ST4 students expressed that the internet is not a very useful tool as only $5.9 \%$ of the students noted its usefulness after finishing the tutoring experience. It is worth noting that tutees and tutors relied on the internet as an important asset before the peer learning by peer tutoring and its reliance in both groups drastically decreased after the experience. It was assumed that parameters such as student interaction might have contributed to improvement in student knowledge and confidence. Students, after the learning experience, expressed more trust in their classmates and their class notes, indicating an increase in self-confidence and confidence among peers. 


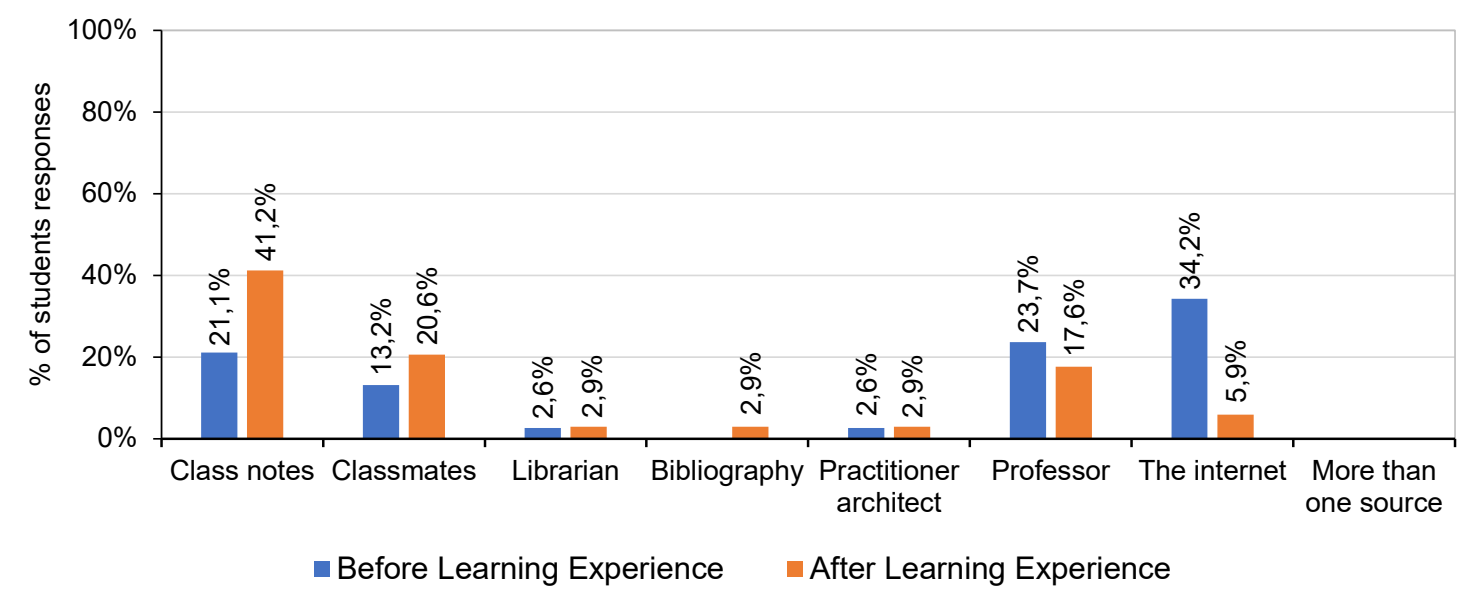

Figure 7. Results from ST4 students to question: From whom/where do you obtain the information to resolve an academic question?

A large number of ST4 students were surprisingly assertive about tutoring their peers before the peer tutoring began (57.9\%). This confidence level further increased after the peer learning was finalized as it increased to $76.5 \%$ of positive replies. Figure 8 invites to think that that the activity solidified student independence and confidence, since Figure 7 showed how ST4 students utilized more often class notes than the professor or the internet. Additionally, the percentage of students who feel confident to mentor someone else rises from $18.4 \%$ to $47.1 \%$. In fact, the tutors described their interactions with their tutees as overwhelmingly positive as $85.3 \%$ of the tutors' responses are 'somewhat good' or 'extremely good'.

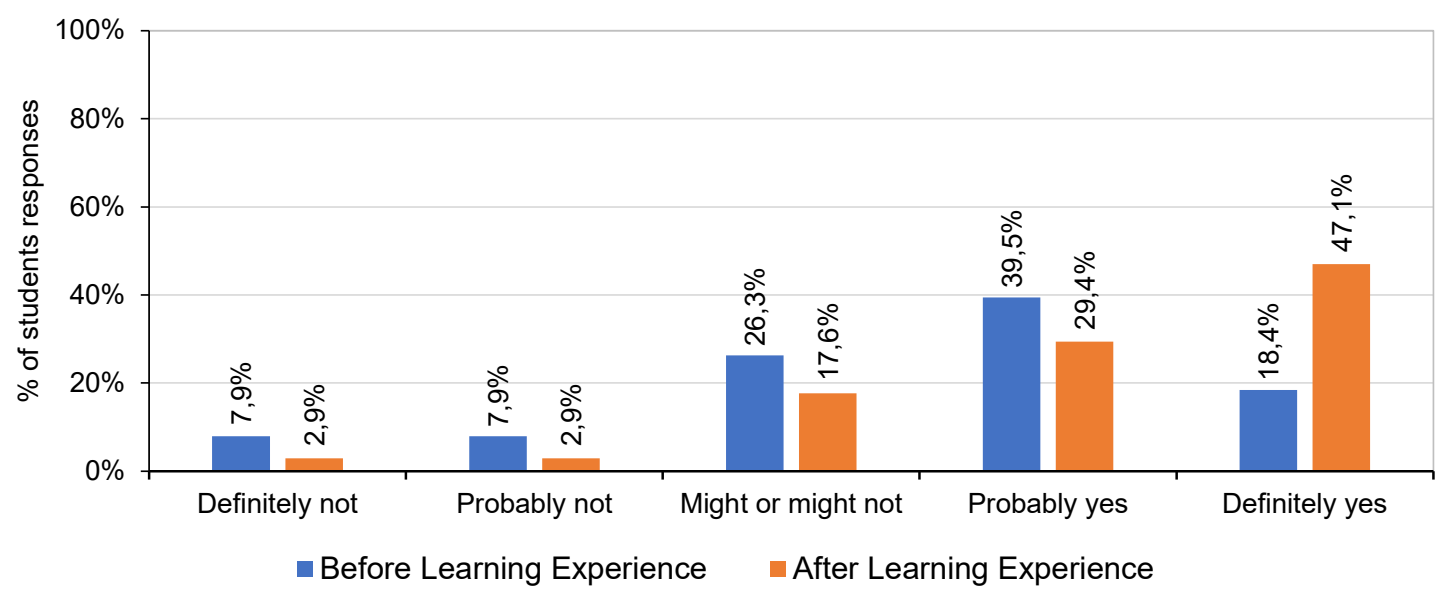

Figure 8. Results from ST4 students to question: Did you feel confident tutoring others in this subject. 
In order to evaluate the success of the peer tutoring, the ST4 students were asked if this active learning experience will be useful for their development as professionals (considering they are in the final year of their undergraduate education). It is worth mentioning that the paired-t test result showed a not significant difference in student responses before and after the activity with $t$ value of 0.72 . However, the overall answers were again very positive, approaching $89.5 \%$ and $70.6 \%$ before and after the assignment respectively. These highly positive responses indicate the success of the peer learning by enriching the learning process and professional skills of the students (Figure 9).

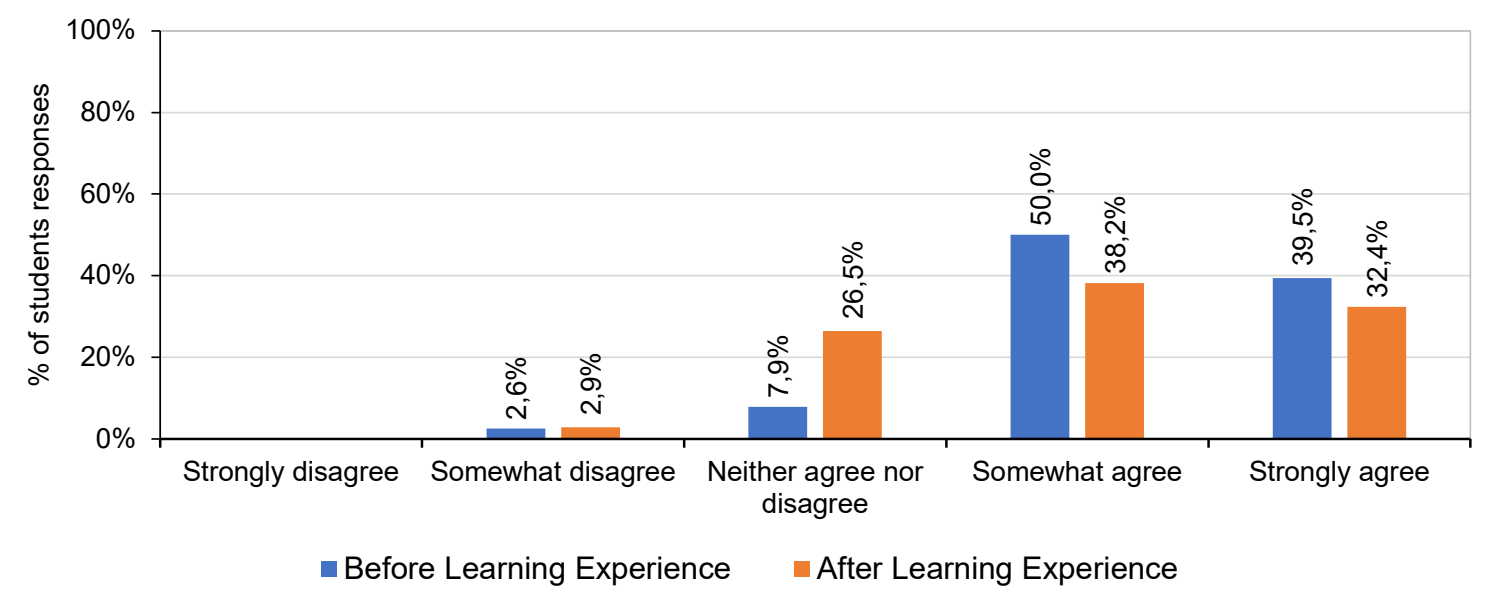

Figure 9. Results from ST4 students to the question: You think that this tutoring has prepared you for a professional activity?

Finally, the tutors (ST4) were asked about the impact of the peer tutoring on their knowledge and commitment to the topic of sustainable design. Figure 10 illustrates that most answers were neutral responses, with $82.4 \%$ of the answers equally distributed between neither high nor low, and high options. The ST4 students were more skeptical about the success of this activity as only $8.8 \%$ of the participants answered 'very high' on acquired knowledge as compared to $35.5 \%$ of ST2 students who gave the same answer (Figure 6). It is also interesting to see that almost 9\% of the ST4 students reported that the improvement on their knowledge was low. With respect to how much this peer tutoring increased their interest in sustainable design, again, most tutors (ST4 students) answered neither 'high' or 'low', which explains that this activity was not very impactful on their commitment to the topic. On the contrary, $35.3 \%$ of the ST4 students believed that the peer learning increased their motivation and interest in sustainable design, rendering the 
learning experience successful and effective. In fact, most tutors would have liked to have peer learning during their past ST2 course (62\%).

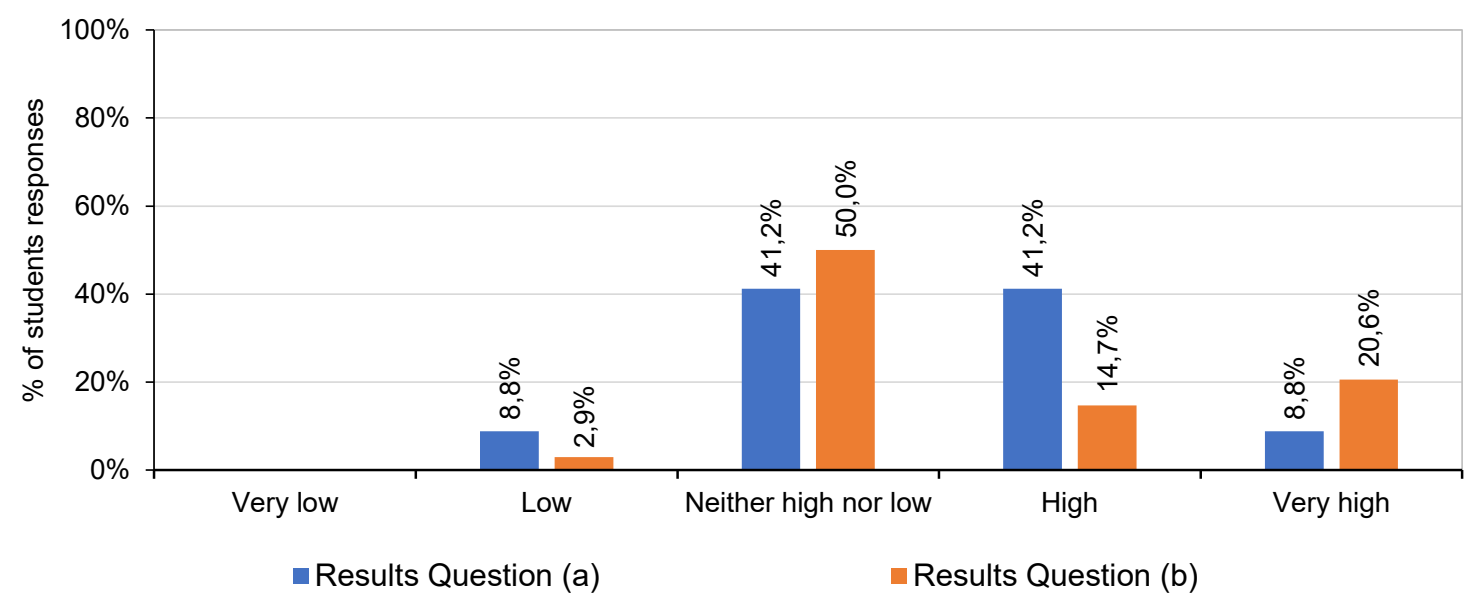

Figure 10. Results from ST4 students to questions: a) To what extent does the proposed peer learning strategy improved your understanding of Sustainable Design? b) To what extent does the proposed peer learning strategy changed your attitude toward Sustainable Design?

\section{Comparison of ST2 Student Performances in Peer Learning}

The exact same sustainable building analysis assignment was undertaken within the ST2 course for three consecutive semesters (Fall 2018, Spring 2019, and Fall 2019). During the first two semesters (Fall 2018 and Spring 2019), the assignment was conducted as a standard part of the course; however, this study is focused on the Fall 2019 semester, when the peer learning by peer tutoring approach was introduced. This methodology allows for the comparison of learning effectiveness and student success by examining the final grades for the assignment with and without the peer learning by peer tutoring component. It is interesting to note that the grades obtained with the standard approach were very consistent: $35 \%$ of the students earned A's and 55\% earned B's in Fall 2018 semester and $55 \%$ of the students earned A's and 30\% earned B's in Spring 2019 semester (Figure 11). These consistent outcomes increase activity's reliability and enable comparisons with this innovative peer learning approach. The ST2 student grades after the peer learning were significantly higher with $81 \%$ of the students earning A's and $19 \%$ earning B's, leaving no student with a grade lower than a B. It is important to mention that the expected quality of work and the grading criteria remained consistent throughout the three semesters; therefore, the different outcomes could be attributed to the increase in the quality of the 
learning experiences after the integration of the peer learning. However, as a limitation of this result it should be acknowledged that this peer learning experience could also not have been the only reason for this grade improvement. However, the academic gap $\left(2^{\text {nd }}\right.$ and $4^{\text {th }}$ year) between mentees and mentors invites to think that there was no direct transfer of solutions from previous good examples. It is also worth mentioning that the overall interest in the topic of sustainability did not substantially changed even after this peer learning (which was focused on architectural sustainable design).

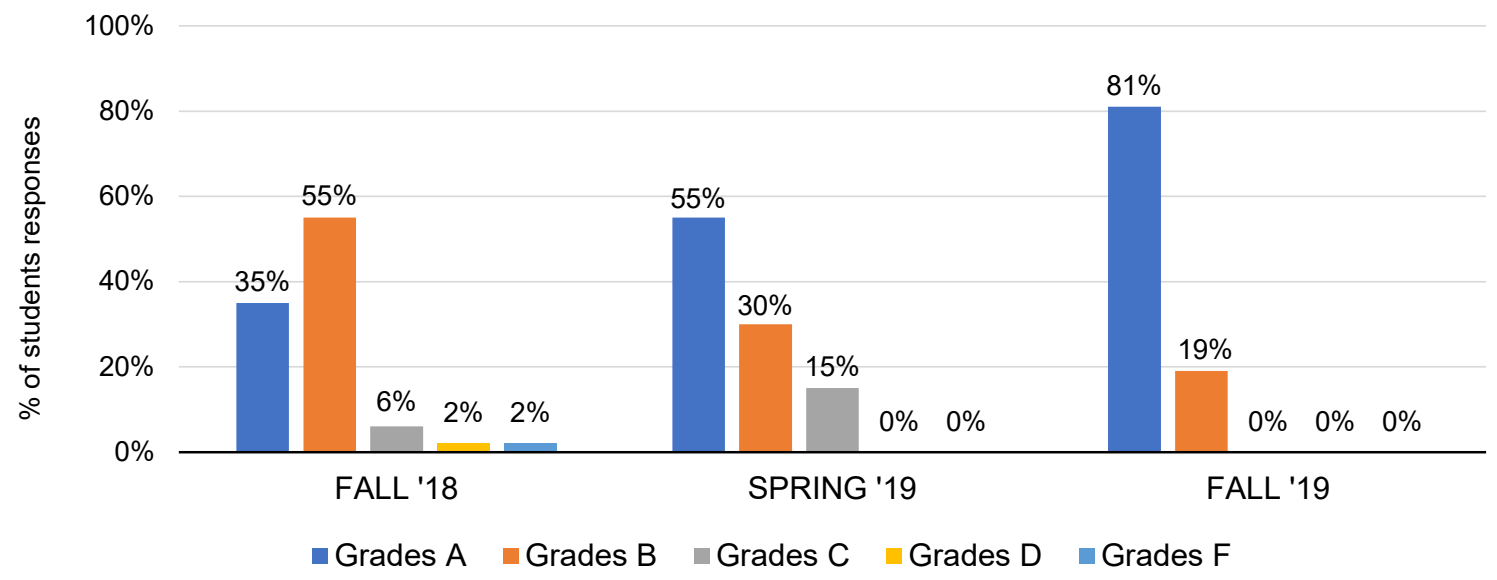

Figure 11. Assignment grading results of the last three semesters (only Fall 2019 using peer learning approach).

\section{Qualitative Responses of ST2 and ST4 students}

In order to provide a full spectrum of students' opinions, an open-ended question was integrated in the surveys. In this question, students were able to share written comments regarding their experiences of peer learning by peer tutoring. A few selected anonymous comments of the ST2 students are as follows: 1) "This assignment was interesting and challenging but we have all benefited from this experience.", 2) "I feel like this project made me realize we have sustainable designs closer that we think and in building I would never have thought of". Additionally, the ST4 student comment says: "I enjoyed this activity because I realized how much I have learned as compared to Principles of Environmental Systems course". Summarized comments from the ST students are as follows: groups worked very well together, the peer-learning activity was fun, having mentors was extremely helpful. Besides these positive comments, there were several negative comments 
on their experiences. For instance, a small number of ST2 students commented that workload among the group members was uneven, and interaction between mentor-mentee was not as fluid as they expected. In regard to the qualitative feedback from the ST4 students, generally positive responses were collected from the majority of ST4 students, underlining the refreshing new approach and how useful the peer tutoring was in order to consolidate their sustainability concepts. Their comments reinforce that the best way of learning is teaching. Although the widely spread positive comments of the ST4 students, there were a few comments mentioning group members' disagreements.

\section{Discussion and Concluding Remarks}

The analysis of three independent surveys carried out among the ST2 and ST4 students at three different stages of the peer learning by peer tutoring (before, during and after) confirms its effectiveness and positive impacts on student learning of sustainability in higher education. The obtained survey responses reflect the growth of students' knowledge, motivation, and commitment to sustainable design throughout both peer learning and peer tutoring experience. In addition, the students gained confidence in discussing and analyzing sustainable design features and systems, and also started implementing professional skills such as communication and collaboration. These professional skills are particularly important in sustainable architecture as it requires all different parties of a design team such as architects, contracts, consultants, clients, etc. to effectively collaborate from schematic design to construction administration phases. Furthermore, the ST2 students expressed a $10 \%$ increase in motivation to learn and apply sustainable design strategies with the help of peer learning experiences. This is understood as a very positive impact when considering that the students registered the course with already high levels of interest and motivation. These positive outcomes were also observed in similar peer learning methodology studies focused in other academic fields such as social sciences (Dehghani et al., 2014; Stone et al., 2013).

The increased effectiveness in work development carried out by ST2 students (tutees) after the peer learning by peer tutoring is also noteworthy. As depicted in Figure 11, this experience resulted in greatly improved final grades compared to the students in previous 
semesters which used conventional approaches while maintaining the same course objectives and grading requirements. Likewise, the work of tutoring helped the ST4 students implement and develop real professional project management, communication of technical concepts, working team management, resolution of conflicts while transmitting ideas to their mentees, coordinating the assignment schedule, and monitoring conducted tasks. However, the presented study acknowledges that a longer duration of the peer learning by peer tutoring would have allowed a steadier development of these skills. As it is described by Manchargo Salvador and Glynn, (Glynn et al., 2006; Manchargo Salvador, 1991), collaboration and interaction with other classmates increases students' ability to acquire skills and knowledge. The present study also encountered several challenges; One of the challenges is the necessity of cooperation between professors of different subjects who have to give parts of their class time to incorporate the peer learning and peer tutoring components. Another difficulty was the different proportion of enrolled students between both courses, named the ST2 and ST4 groups. Taking into account the previous observations, the initial recommendations for any academic seeking to explore peer learning activities in their own teaching would be focused on group sizes and the interaction among them:

- An ideal research setting would be that a number of tutors to be a half or two-thirds of the number of tutees since a smaller ratio would make it more difficult pairing them up and the peer tutoring sessions would be more challenging. Additionally, for ideal performance mentors and mentees should not have any kind of relationship, so in order to avoid this the instructor should aleatorily create the pairing between ST2 and ST4.

- The number of tutors by group should not exceed two since it is critical for them to have support of each other, and a higher number can cause new roles that could jeopardize the performance.

- It is essential for the correct development of the peer learning and peer tutoring protocols to detect dysfunctional groups and to respond to them as quickly as possible. If these groups are identified, a parallel activity should be integrated in order to cover the same topics with a different approach. Therefore, it is necessary to develop mechanisms to recognize those dysfunctional groups as soon as possible. 
The present case study confirms that peer learning by peer tutoring in architecture courses of sustainable design has a very positive effect in student performance and their learning experiences. In addition, this study has an added value for applying an innovative double peer learning process in the methodology by introducing peer tutoring in two different courses where the ST2 students took the role of tutees and the ST4 students took the role of tutors. The assessments of the students' surveys and the final academic results shows that this learning pedagogy increased the effectiveness of the course. Approximately $75 \%$ of the students believe that this peer learning strategy improved their understanding of sustainable design. Moreover, the interaction of the two courses' students was smooth, easygoing and highly valued by most of them. It also created an increased motivation in the subject of sustainable design as well as an improved self-confidence as more than $22 \%$ of the students felt more prepared as future professionals. At the same time, the learning experience allowed the ST4 students to work through professional skills such as the communication of technical concepts, project management, working team management, resolution of conflicts, etc., that are otherwise difficult to put into practice in an academic environment. It is worth mentioning that one of the most effective teaching methods would be merging active learning strategies with traditional approaches. Theis combination allows to increase student and instructor's motivation and improves teaching methodologies.

In this case study, it is important to note that some students' questions to the professor are recurrent, therefore, these students' opinions should be monitored closely to adapt future peer learning activities.

Although there are always variations due to the idiosyncrasy of working with students with two different course levels, the most challenging aspect has been the duration of the activity. It would be recommended, if possible, to create activities that last at least a month in order to create meaningful number of interactions among students. This is a very common disadvantage in this type of study, where the assessed activity has to stick to an academic pre-established agenda and schedule. A significant recommendation would also to be prepared for any potential difficulties along the activity and be able to adapt accordingly. For future research, the introduced peer learning by peer tutoring methodology should be 
repeated in subsequent courses with extended duration of the study. Finally, the last suggestion would be to provide an identification code for each student in order to track their personal progresses and correlations. Nevertheless, this practice could rise privacy concerns if the code-identity information is not handled properly.

\section{References}

Álvarez Valdivia, I. (2008), "La coevaluación como alternativa para mejorar la calidad del aprendizaje de los estudiantes universitarios: Valoración de una experiencia", Revista Interuniversitaria de Formación Del Profesorado, Vol. 22 No. 3, pp. 127-140.

Barth, M. and Michelsen, G. (2013), "Learning for change: An educational contribution to sustainability science”, Sustainability Science, Vol. 8 No. 1, pp. 103-119.

Boarin, P., Martinez-Molina, A. and Juan-Ferruses, I. (2020), "Understanding students' perception of sustainability in architecture education: A comparison among universities in three different continents", Journal of Cleaner Production, Elsevier Ltd, Vol. 248, p. 119237.

Boud, D. (2001), "Making the move to peer learning", Peer Learning in Higher Education: Learning from and with Each Other, No. January 2001, pp. 1-20.

Boud, D., Cohen, R. and Sampson, J. (2002), "Books. Peer Learning in Higher Education: Learning From and With Each Other", Education + Training, Vol. 44 No. 6, p. 19.

Boud, D. and Lee, A. (2005), "Peer Learning as pedagogic discourse for research education", Studies in Higher Education, Vol. 30 No. 5, pp. 501-516.

Budge, K., Beale, C. and Lynas, E. (2013), "A chaotic intervention: Creativity and peer learning in design education", International Journal of Art and Design Education, Vol. 32 No. 2, pp. 146-156.

Cheng, D. and Walters, M. (2009), "Peer-assisted learning in mathematics: An observational study of student success", Journal of Peer Learning Volume, Vol. 2 No. 1, pp. 23-39.

Corral Manuel de Villena, I., Núñez Andrés, A., Rodríguez Jordana, J.J. and Buill Pozuelo, F. (2012), "Proyecto geomático: Una aplicación práctica de integración de conocimientos", CIDUI Congrés Internacional de Docència Universitària i Innovació. Barcelona, 4, 5 i 6 de Juliol, 2012, Universitat Pompeu Fabra, Barcelona, pp. 1-6.

Dehghani, M.R., Amini, M., Kojuri, J. and Nabeiei, P. (2014), "Evaluation of the efficacy of peer-learning method in nutrition students of Shiraz University of Medical Sciences.", Journal of Advances in Medical Education \& Professionalism, Vol. 2 No. 2, pp. 71-76.

Disterheft, A., Caeiro, S.S., Leal Filho, W. and Azeiteiro, U.M. (2016), "The INDICARE-model Measuring and caring about participation in higher education's sustainability assessment", Ecological Indicators, Elsevier Ltd, Vol. 63, pp. 172-186.

Evnitskaya, N. (2008), “El contrato didáctico entre estudiantes: análisis del trabajo en parejas en el aula de Aprendizaje Integrado de Contenidos y Lengua (AICLE)", Proceedings of the VIII Congress on General Linguistics., Universidad Autonoma de Madrid, Madrid.

Fateh Ali Khan, H., Akash, A., Avinash, R. and Lokesh, C. (2018), "WebRTC Peer to Peer Learning", International Journal of Engineering Research And, Vol. V7 No. 03, pp. 233238. 
Finelli, C.J., Klinger, A. and Budny, D.D. (2001), "Strategies for improving the classroom Environment", Journal of Engineering Education, Vol. 90 No. 4, pp. 491-497.

Glynn, L.G., MacFarlane, A., Kelly, M., Cantillon, P. and Murphy, A.W. (2006), "Helping each other to learn - A process evaluation of peer assisted learning", BMC Medical Education, Vol. 6 No. 18, pp. 1-9.

Griffiths, S., Houston, K. and Lazenbatt, A. (1995), Enhancing Student Learning through Peer Tutoring in Higher Education: A Compendium Resource Pack with Case Study Contributions, University of Ulster.

Haller, C.R., Gallagher, V.J., Weldon, T.L. and Felder, R.M. (2000), "Dynamics of peer education in cooperative learning workgroups", Journal of Engineering Education, Vol. 89 No. 3, pp. 285-293.

Huang, S. and Pierce, E. (2015), "The impact of a peer learning strategy on student academic performance in a fundamental engineering course", Proceedings - Frontiers in Education Conference, FIE, IEEE, pp. 1-4.

Keppell, M., Au, E., Ma, A. and Chan, C. (2006), "Peer learning and learning-oriented assessment in technology-enhanced environments", Assessment and Evaluation in Higher Education, Vol. 31 No. 4, pp. 453-464.

Leal Filho, W., Shiel, C., Paço, A., Mifsud, M., Ávila, L.V., Brandli, L.L., Molthan-Hill, P., et al. (2019), "Sustainable Development Goals and sustainability teaching at universities: Falling behind or getting ahead of the pack?", Journal of Cleaner Production, Vol. 232, pp. 285-294.

Manchargo Salvador, J. (1991), El Profesor y El Autoconcepto de Sus Alumnos: Teoría y Práctica, Escuela Española, Madrid.

Marsh, H.W. (1982), "SEEQ: A reliable, valid, and useful instrument for collecting students' evaluations of university teaching", British Journal of Educational Psychology, Vol. 52 No. 1, pp. 77-95.

Martin, M. and Edwards, L. (1998), "Peer Learning on fieldwork placements", British Journal of Occupational Therapy, Vol. 61 No. 6, pp. 249-252.

Mavromatidis, L. (2018), “Coupling architectural synthesis to applied thermal engineering, constructal thermodynamics and fractal analysis: An original pedagogic method to incorporate 'sustainability' into architectural education during the initial conceptual stages", Sustainable Cities and Society, Vol. 39 No. December 2016, pp. 689-707.

Nicol, D. and Pilling, S. (2005), Changing Architectural Education: Towards a New Professionalism, Taylor \& Francis.

Pelsmakers, S., Donovan, E., Moseng, K. and Eyebye, B. (2019), "Developing Architecture Studio Culture : Peer-Peer Learning", Education, Design and Practice-Understanding Skills in a Complex World AMPS, Stevens Institute of Technology Stevens Institute of Technology New Jersey/New York: 17-19 June, pp. 264-272.

Rodarte-Luna, B. and Sherry, A. (2008), "Sex differences in the relation between statistics anxiety and cognitive/learning strategies", Contemporary Educational Psychology, Vol. 33 No. 2, pp. 327-344.

Salmerón, H., Rodríguez-Fernández, S. and Gutiérrez-Braojos, C. (2010), "Methodologies to improve communication in virtual learning Environments", Comunicar: Revista Científica Iberoamericana de Comunicación y Educación, Vol. 34 No. 17, pp. 163-171. Sanmartí, N. (2007), 10 Ideas Clave: Evaluar Para Aprender, Padres y Maestros / Journal of Parents and Teachers, Vol. 0, Graó, Barcelona, available 
at:https://doi.org/10.14422/pym.i370.y2017.002.

Secomb, J. (2008), "A systematic review of peer teaching and learning in clinical education", Journal of Clinical Nursing, Vol. 17 No. 6, pp. 703-716.

Slavin, R.E. and Johnson, R.T. (1999), Aprendizaje Cooperativo: Teoría, Investigación y Práctica, Aique, Buenos Aires, available at:https://doi.org/10.2307/29740001.

Stone, R., Cooper, S. and Cant, R. (2013), "The value of Peer Learning in undergraduate nursing Education: A systematic review", ISRN Nursing, pp. 1-10.

Stump, G.S., Hilpert, J.C., Husman, J., Chung, W.T. and Kim, W. (2011), "Collaborative learning in engineering students: Gender and achievement", Journal of Engineering Education, Vol. 100 No. 3, pp. 475-497.

Topping, K. (2015), "Peer tutoring: Old method, new developments", Infancia y Aprendizaje, Routledge, Vol. 38 No. 1, pp. 1-29.

United Nations General Assembly. (2015), "Sustainable Development Goals", available at: https://sustainabledevelopment.un.org (accessed 2 January 2021).

Valls, F., Redondo, E., Fonseca, D., Torres-Kompen, R., Villagrasa, S. and Martí, N. (2018), "Urban data and urban design: A data mining approach to architecture education", Telematics and Informatics, Elsevier, Vol. 35 No. 4, pp. 1039-1052.

Webb, N.M. (1989), "Peer interaction and learning in small groups", International Journal of Educational Research, Vol. 13, pp. 21-39. 